Article

\title{
Omni-Chanel Network Design towards Circular Economy under Inventory Share Policies
}

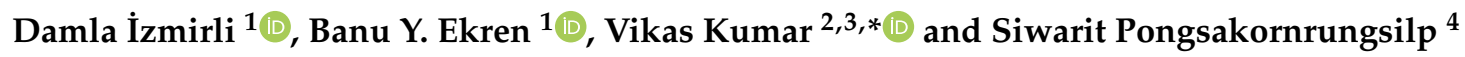 \\ 1 Department of Industrial Engineering, Faculty of Engineering, Yasar University, Izmir 35100, Turkey; \\ damla.izmirli@outlook.com (D.İ.); banu.ekren@yasar.edu.tr (B.Y.E.) \\ 2 Bristol Business School, University of the West of England, Bristol BS16 1QY, UK \\ 3 Faculty of Accounting, Ton Duc Thang University, District 7, Ho Chi Minh City 729000, Vietnam \\ 4 Department of Business Administration, School of Management, Walailak University, \\ Nakhon Si Thammarat 80160, Thailand; psiwarit@wu.ac.th \\ * Correspondence: vikas.kumar@uwe.ac.uk
}

Citation: İzmirli, D.; Ekren, B.Y.; Kumar, V.; Pongsakornrungsilp, S. Omni-Chanel Network Design towards Circular Economy under Inventory Share Policies.

Sustainability 2021, 13, 2875.

https://doi.org/10.3390/su13052875

Academic Editors:

Gianmarco Bressanelli,

Federico Adrodegari, Daniela

Cristina Antelmi Pigosso and

Vinit Prida

Received: 3 February 2021

Accepted: 4 March 2021

Published: 7 March 2021

Publisher's Note: MDPI stays neutral with regard to jurisdictional claims in published maps and institutional affiliations.

Copyright: (c) 2021 by the authors. Licensee MDPI, Basel, Switzerland. This article is an open access article distributed under the terms and conditions of the Creative Commons Attribution (CC BY) license (https:// creativecommons.org/licenses/by/ $4.0 /)$.

\begin{abstract}
In this paper, we study inventory share policies in an omni-channel supply network, to contribute to the circular economy (CE) concept. Lateral inventory share implementation provides flexibility and profitability in the supply chain by allowing inventory share between the same echelon locations in a network. Total holding costs and transportation costs can be reduced by lateral inventory share applications, which also contribute to decreased material usage for production over time, as well as reduced $\mathrm{CO}_{2}$ emission released by transportation. Technological and Internet of Things (IoT) developments make it possible for companies to share their real-time information with each other for uninterrupted marketing experiences. With such a connected network, companies aim to increase their profitability and responsiveness to their customers. We explore a well-designed inventory share policy towards the CE concept under an $(s, S)$ inventory control policy. We simulate several pre-defined share designs by Arena 16.0 commercial software and compare their performances in terms of cost, responsiveness, transportation frequency, inventory held, etc. The results show that, by the implementation of a well-designed lateral inventory share policy, an omni-channel network can benefit from decreased holding cost and transportation cost, contributing to the CE concept.
\end{abstract}

Keywords: omni-channel; circular economy; $\mathrm{CO}_{2}$ emission; inventory share; IoT; e-commerce; $(s ; S)$ inventory; inventory control; customer sustainability

\section{Introduction}

By the new channels that have emerged with the widespread use of the internet and mobile devices, the integration of these new channels has led to changes in retail strategies and customer expectations [1]. The recent rapid technological developments have also contributed to those new marketing strategy changes from single-channel to multi-channel, cross-channel, and omni-channel commerce [2,3].

E-commerce is one of the most important channels in marketing, providing uninterrupted and fast service experiences. For instance, by the recent Covid-19 lockdowns, e-commerce shopping experiences have increased drastically. In many countries, consumers tend to buy online alternative to physical shopping [4]. Changing customer expectations and increasing consumer needs have forced retailers to re-design their marketing channels [5]. For that, physical and online channels are managed together by becoming complementary concepts. Retailers tend to implement an integrated management strategy in which multiple channels are connected [1] by sharing real-time information in order to reach many customers and meet their expectations. That radical change in retailing is referred to as omni-channel marketing in literature.

Omni-channel strategy is the synergistic management of multiple channels and customer contact points in an integrated manner in order to meet customer expectations in 
the best way [1]. With the recent digitalization concept, supply networks tend to be more connected, more transparent, and more adaptive to real-time changes. The aim of the omnichannel retailing strategy is developed by the recent digitalization target of companies, to provide customers with a more consistent and more reliable service without interruption in the transition between channels by coordinating all channels and processes together [1].

However, it is highly possible to experience demand uncertainty in omni-channel, due to operational differences between online and offline repositories. Those large connections and fluctuations reveal the importance of the determination of correct inventory and logistics management policies in the network. Retailers search for new inventory control implementations and practices that could meet customer demand faster while reducing total cost. In order for the supply chain to be successful, it can be provided to market changes and with products that better meet customer expectations [6]. By a well-designed inventory share policy among stocking locations, a supply chain system may become more flexible, responsive, and profitable [7]. Lateral inventory share may ensure rapid response to customer demand and increase customer service level by transferring the other member's excess inventory to the starving ones that cannot meet the customer demand in the network $[8,9]$. This implementation may also lead to reduced inventory holding amount in the network.

Recent increasing environmental problems also increase the danger of depletion of natural resources. Policymakers and companies increasingly include sustainability concerns on their agendas and companies' strategies [10]. Recent concerns on environmental issues have led researchers to develop novel approaches for the management of systems, resulting in decreased negative environmental effects. For instance, by a welldesigned omni-channel network design, it is possible to manage cost efficiency in the supply network by decreased transportation from suppliers and inventory held in the network. Reduced transportation will also contribute to reduced carbon emission. Besides, reduced inventory holding will also contribute to reduced risk for unnecessary material used during production.

The resource scarcity problem that may arise requires companies to be more conscious about environmental awareness and to take precautions in this regard. It is well known that the circular economy (CE) seeks to maximize the value of materials circulating within the economy as well as minimize material consumption [11,12]. CE is a concept that encompasses activities that minimize, reuse, and recycle materials used in production, distribution, and consumption processes [13]. Figure 1 shows the main concept of CE. It also looks for ways to prevent waste from building up and reduce hazardous components in waste and products. From Figure 1, it is understood that production and transportation phases also play a significant role in this concept. In this study, from a CE perspective, we mostly contribute this concept by decreased inventory carried in the network, resulting in decreased material usage in production and in decreased transportation from the upper echelon supplier, resulting in decreased carbon emission in distribution.

In the transition to $\mathrm{CE}$, digital technologies take an important place by optimizing material flows and enabling reverse material flows [14]. With Industry 4.0 technological and IoT-based developments, real-time communication and synchronization of members of supply chains have become easy and possible. Therefore, efficient management of inventory share applications among locations can contribute not only to the decreased holding inventory performance metric, but also to the decreased transportation frequency from the main depot, contributing to the circular economy concept significantly.

This work aims to study the effects of lateral inventory share policies on a digitized omni-channel supply chain network, where each stage in the network shares real-time inventory and demand information between each other. Our goal is to find out welldesigned inventory share policies minimizing total network cost and ensuring customer satisfaction by product availability. We also aim to ensure environmental sustainability by reduced transportation from the main depot and inventory requirement in the network. We pre-define six inventory share policies and simulate them by using the Arena 16.0 
commercial software. We implement an $(s, S)$ inventory control policy, where $s$ is the re-order point, and $S$ is the order-up-to level of the inventory level. We aim to find out the optimal costs under $(s, S)$ decision variables by using the OptQuest tool in that software.

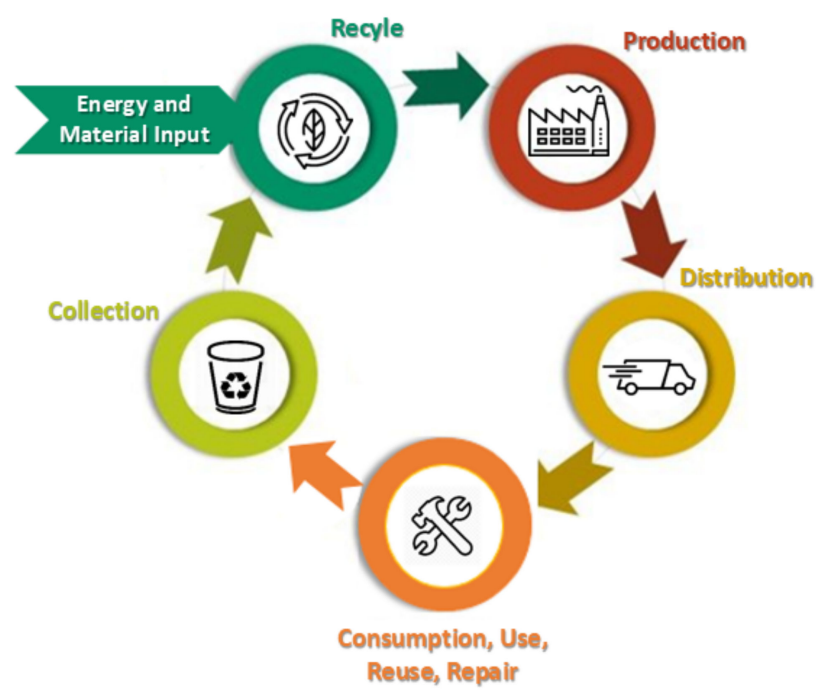

Figure 1. Circular economy (CE) concept.

This study is organized as follows. In Section 2, a literature review on related studies is presented. In Section 3, a description of the studied problem, methodology, and developed policies are explained. The results and analyses are presented in Chapter 4 and Chapter 5. Chapter 6 provides a conclusion part.

\section{Literature Review}

Digitalization as a result of technological developments affects consumer behavior and hence retailer's marketing strategies [15]. With the increase of digital channels, integration of those channels has emerged, and the ability to serve customers from more than one channel has become a very important issue for retailers. Through that, companies can expand their markets by reaching many new customers. Through an integrated channel concept, retailers can offer their customers a shopping experience through a physical store, online channels, mobile applications, and many other channels. By that experience, boundaries are eliminated by providing integration between physical and online channels. All those affect consumer expectations and reveal the expectations of being able to shop without interruptions between all channels.

A multi-channel strategy can be defined as companies selling products by allowing customers to shop through different channels [3,16]. Rangaswamy et al. [17] state that multi-channel customer sustainability can be achieved by providing products, information, service, and support to customers by an integrated channel rather than a single channel. Still, multi-channel applications are not enough to meet today's consumers' expectations through seamless shopping demand across channels. That has created the concept of omni-channel marketing strategy. Lazaris and Vrechopoulos [18] complete a comprehensive literature review by also emphasizing that the omni-channel is developed from the multi-channel concept. In their study, they define the omni-channel strategy as a marketing distribution strategy in which channels are used together and without interruption. Beck and Rygl [5] classify the terms multi-channel, cross-channel, and omni-channel according to the degree of customer interaction and company integration. Yadav et al. [19] develop a mathematical model for the optimal design of an omni-environment. The result shows that omni-channel integration performs better than the classical supply chain network.

Although the omni-channel strategy has an advantage in terms of customer satisfaction and sustainability, inventory and logistics management may become difficult in 
this network due to increased demand variability and uncertainty under the integration. Lateral inventory share implementations may prevent disadvantages, caused by that omnichannel environment. It is an effective source sharing among the same echelons in the network to prevent stock shortages [9].

Lee et al. [20] propose a lateral transshipment policy called SLA, in which the service level is taken into account in order to decide the amount of lateral transshipment. Ekren and Arslan [21] apply inventory share policies by transshipping the products between stocking locations. They consider $(s, S)$ inventory control policy with three depots. They compare the results of the lateral transshipment policies with the non-lateral share case and find that lateral transshipment performs well. Herer et al. [22] prove that the most effective replenishment policy to reduce the long-term expected cost in a system with a supplier and multiple dealers is the order up to policy. Ekren et al. $[23,24]$ examine the inventory control problem by developing the $(s, S)$ inventory model in which they use simulation optimization procedures. Glazebrook et al. [25] propose a hybrid policy for a system and they developed a quasi-myopic heuristic method to determine how the proposed hybrid transmissions will occur. Through the widespread use of e-commerce, the online channels that can share real-time information, and the problems that arise in those systems, lateral inventory share applications might be suitable to handle those problems. Zhao et al. [26] use lateral transshipment to decrease the inventory risk created by demand uncertainty caused by a new trading model, online-offline (OTO). They determine that lateral transshipment provides positive results in the OTO commercial model. İzmirli et al. [27] develop lateral inventory share policies for a sustainable omni-channel system under an IoT environment. The findings of their studies show that by lateral inventory share implementations, customer satisfaction increases, while total network cost and environmental negative impacts decrease.

In order for organizations to remain competitive, economic, environmental, and social priorities must be balanced in global operations. The circularity of business models and supply chains is an important element for sustainable production, which is necessary to improve the economic and environmental performance of countries [10]. Businesses transform their supply chains into a more environmentally friendly structure in order to reduce their waste and environmental risks $[10,28]$. Today, businesses benefit from the CE strategy, in which the products they produce can be associated with ecology and economic growth [11,28]. Govindan and Hasanagic [29] conduct a systematic review determining drivers, barriers, and practices related to the implementation of the CE in supply chains. They present a multi-perspective framework. Genovese et al. [30] analyze case studies from two different industries and compare traditional and circular production systems. They determine that using a CE in an integrated manner with a sustainable supply chain has positive effects on the environment. Soysal et al. [31] address the multi-echelon beef logistics network problem. For this problem, they develop a multi-objective linear programming model by reducing logistics costs and $\mathrm{CO}_{2}$ emissions. Abad-Segura et al. [32] examine CE policies in 2004-2019 and analyze research trends towards environmental and sustainable growth. Milios [33] studies a mixed-method approach that uses various sources to analyze the characteristics of different taxation measures (a raw material resource tax, reuse/repair tax relief, and a waste hierarchy tax at the end of life of products).

The widespread use of digital technologies such as Industry 4.0 and its main components, Big Data and IoT, can also contribute to the transition to the CE concept. Windapo and Moghayedi [34] examine the use of intelligent technologies in buildings to measure their impacts on CE. Industry 4.0 developments facilitate the applicability of lateral inventory share in supply chains, which contributes to environmental sustainability. Nakandala et al. [35] propose a lateral inventory transshipment model for perishable products to integrate and improve the deterioration as well as other related costs. Results show that lateral transshipment is a well-performing strategy to minimize the total cost of decision rules in cost scenarios. Ekren et al. [36,37] model a single-echelon network design with three online markets aiming to minimize food waste in the network of the supply chain. 
They use a simulation technique to compare the performances of the food supply chain where the lateral inventory share strategy is applied. Jose et al. [38] conclude that artificial intelligence and related technologies can increase energy efficiency through CE vision.

Different from the existing literature, in this paper, we study lateral inventory share policies in an omni-channel supply network. By that, we also examine the contribution of lateral inventory share implementations on the CE concept. By lateral inventory share implementations, we aim to reduce inventory held in the network as well as transportation from upper echelon suppliers. As a result, we aim to contribute to the CE concept mainly from production and distribution phases as shown in Figure 2. For instance, by lateral inventory share, the inventory amount carried in the network can be reduced. Hence, production and material usage due to excess production because of demand variability can be prevented. Moreover, decreased network cost and material usage, as well as decreased $\mathrm{CO} 2$ emissions, can be realized. There are both online and offline stores connected to each other under an IoT environment. We aim to optimize the total cost of the network under pre-defined lateral inventory share policies and compare the results to select the best one. We consider an $(s, S)$ inventory control policy where " $s$ " and " $S$ " represent the re-order point and order-up-to-levels for replenishments.

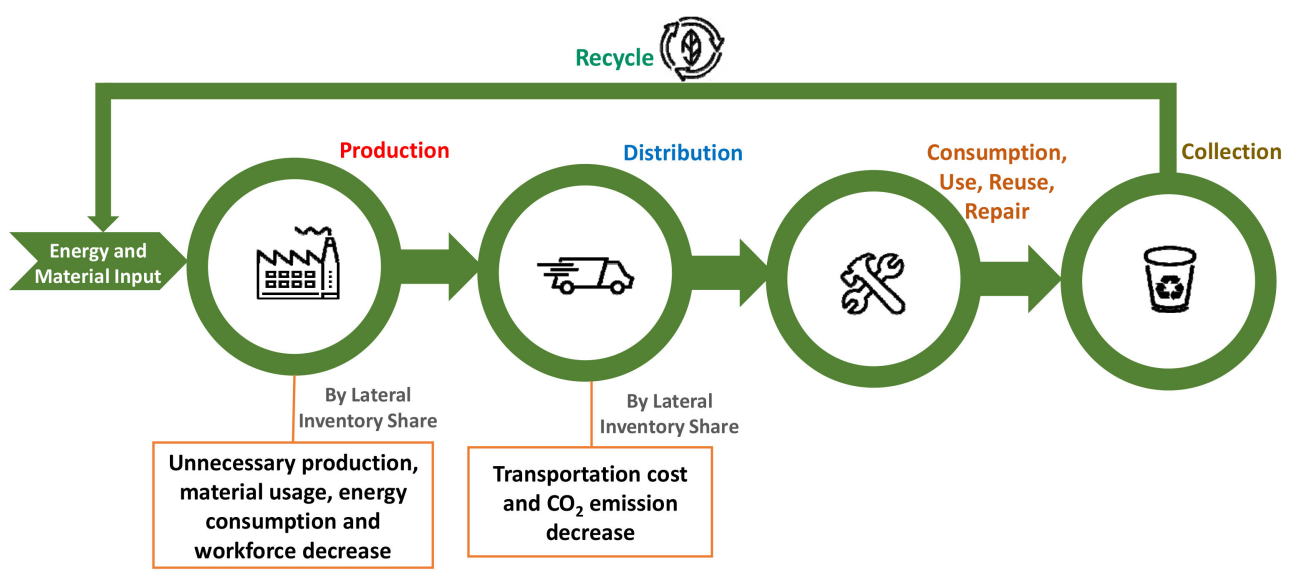

Figure 2. Contribution of lateral inventory share applications towards CE concept (Source: Authors).

\section{Materials and Methods}

\subsection{Problem Definition}

In this study, we study an omni-channel supply network where online/offline stores are connected under an IoT environment so that they can share their inventory information with each other. Through today's technological developments, it is possible to have endto-end supply chain connectivity throughout a supply network. Through that, the stores aim to increase network efficiency as well as responsiveness. As mentioned, that would also contribute to the $\mathrm{CE}$ concept by reduced holding inventory throughout the network as well as reduced transportation from the upper echelon.

In the network, we assume that there are three companies, each of which has its own online and offline stores. Inventory share policies are pre-determined for online and offline stores, separately. Each store makes product replenishments from an upper-echelon (i.e., main depot). Figure 3 shows the considered network's figure. The dash arrows represent information transfer, and the straight lines represent the product flows among stages. 


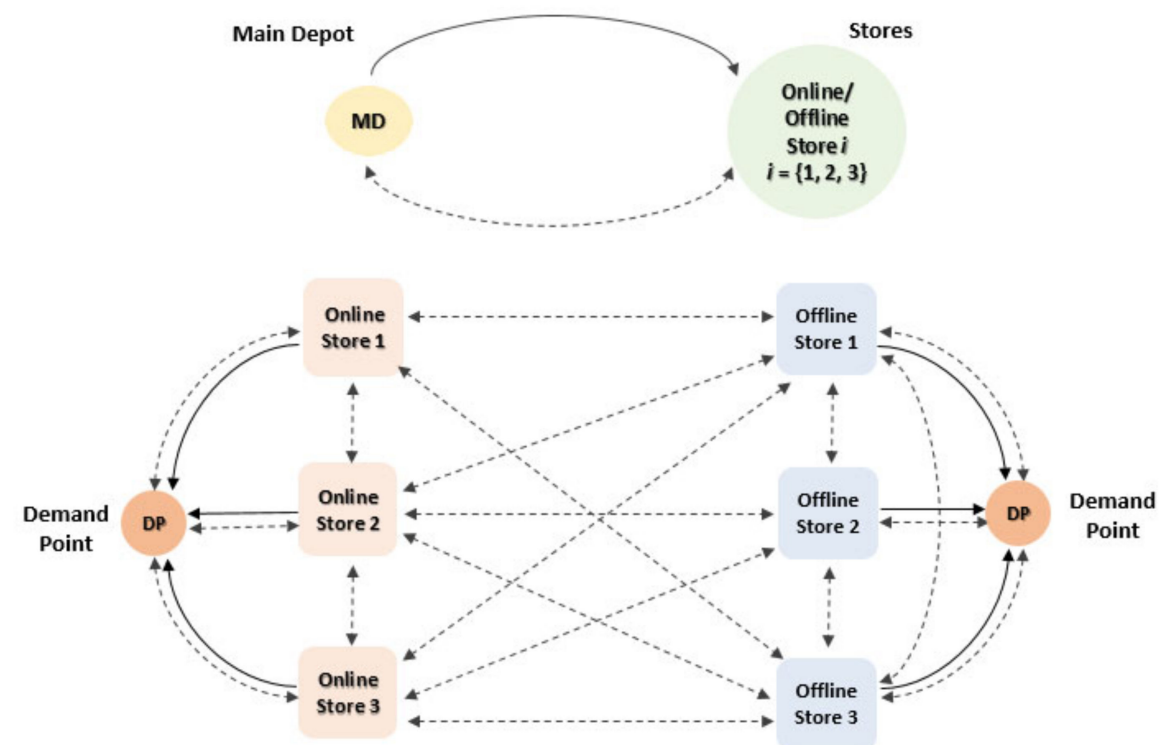

Figure 3. The studied omni-channel system (Source: Authors).

In Figure 3's network, although solid lines from online/offline stores to demand points may change based on the pre-defined lateral inventory share policy considered, we show all possible product flows here, at the highest connection level. After simulating each predefined lateral inventory share policy, we optimize (i.e., minimize) the total inventory cost in the system, under a continuous $(s, S)$ inventory control policy. Here, $s$ and $S$ represent the re-order point and order-up-to level for the replenishment policy. The re-order point is the inventory level when the store orders from the main depot for replenishment. Orderup-to level is the inventory level to define how many to order from the upper echelon. To test how results change under lost sale cost, we complete the optimization procedure for three different lost sale cost scenarios: $\$ 5, \$ 10$, and $\$ 20$ per product. The optimization is completed by the OptQuest optimization tool provided in the Arena 16.0 simulation software developed by Rockwell Automation.

In the simulation models, the considered assumptions are summarized in Section 3.2.

\subsection{Simulation Model Assumptions}

The omni-channel network assumptions are as follows:

- At the same echelon level, six stores, three of which belong to e-stores and three belonging to offline stores, are considered.

- There is a single type of product in the network.

- Demand amount distribution for each depot has a separate mean: Online 1 Normal $(70,20)$, Online 2 Normal $(50,20)$, Online 3 Normal $(90,20)$, Offline 1 Normal $(35,20)$, Offline 2 Normal $(25,20)$, and Offline 3 Normal $(45,20)$.

- The main depot supplies products with unlimited capacity.

- While calculating the amount of replenishment for depot $i$ at time $t, Q_{i t}$, products on road are counted as on hand.

- The capacity of a truck sent from the main warehouse is 100 products. There is infinite numbers of trucks in the system.

- $\quad(s, S)$ levels are optimized separately for each store.

- Inter-arrival time for demands follows an exponential distribution with a mean of $24 \mathrm{~h}$.

- Lead time from the main depot to any store is considered to have a uniform distribution with parameters $(1,2)$ days.

- The optimization procedure is aimed to have at least a $95 \%$ fill rate constraint. Here fill rate is the ratio of meeting demand from on hand.

- Simulation models are run for 365 days with ten independent replications. 
- The warm-period is determined by the eye-ball technique as two months.

- Offline stores are assumed to have a maximum of 200 products capacity to carry.

- Total network cost is computed by considering ordering, transportation, holding, inventory share, and lost sale costs.

- CRN (Common Random Numbers) variance reduction technique is used to ensure that the random values in the simulation models are consistent across all models.

The simulation models are verified and validated by debugging and animating the models. The utilized notations are summarized in Section 3.3.

\subsection{Notations Considered in the Simulation Models}

The notations that are utilized in the simulation models are as follows:

si: Re-order inventory level at store $i, i=\{1,2,3,4,5,6\}$.

$S_{i}$ : Up-to-level at store $i, i=\{1,2,3,4,5,6\}$.

$k$ : Total number of stores in the network.

$d_{i t}$ : Incoming amount of demand at online/offline store $i$ at time $t, i=\{1,2,3,4,5,6\}$.

$C_{T}$ : Truck capacity from the main depot (i.e., 100 products per truck).

$I_{i t}$ : Current inventory level at store $i$, at time $t$.

$I S_{j i}$ : Inventory share cost per product from store $j$ to $i, j \neq i, i=\{1,2,3,4,5,6\}, j=\{1,2,3,4$, $5,6\}$.

$L_{j i t}$ : The amount of products shared from store $j$ to store $i$ at time $t$.

$T_{C}$ : Fixed truck cost for a single truck (i.e., $\$ 100$ per truck).

$L S_{i t}$ : Lost sale amount at store $i$ at time $t, i=\{1,2,3,4,5,6\}$.

$Q_{i t}:$ Replenishment amount sent from main depot to store $i$, at time $t, i=\{1,2,3,4,5,6\}$.

$T Q_{c}$ : Total ordering cost at the end of the simulation run.

$\mathrm{TT}_{c}$ : Total transportation cost at the end of the simulation run.

$T Q$ : Total replenishment amount from the main depot at the end of the simulation run.

$T L S_{C}:$ Total lost sale cost at the end of the simulation run.

TIS $_{C}$ : Total inventory share cost at the end of the simulation run.

$T H_{C}$ : Total holding cost at the end of the simulation run.

$T D_{\mathrm{i}}$ : The total amount of demand arrived at store $i$, at the end of the simulation run.

$Q R_{i t}:$ The amount of products on road from the main depot to store $i$, at time $t, i=\{1,2,3,4$, $5,6\}$

$n_{i t}$ : Number of trucks sent from the main depot to store $i$, at time $t$ (i.e., an integer).

$C_{o}$ : Ordering cost per product from the main depot.

LSc: Lost sale cost per product.

$I_{t}$ : The total amount of inventory in the network at time $t$.

$I_{A V G}$ : Annual average inventory carried on hand.

$F L_{\mathrm{i}}$ : Fill rate for store $i, i=\{1,2,3,4,5,6\}$.

$T$ : $\quad$ Simulation run time (i.e., 365 days).

The set values for the considered parameters are: $I S_{j i}=\$ 1$ if the product is shared between online and offline depots for the same companies and at $\$ 1.5$ for the different companies. $C_{o}=\$ 1.5$. $Q_{i t}$ and $T Q$ are calculated by (1) and (2), respectively.

$$
\begin{gathered}
Q_{i t}=\left\{\begin{array}{cc}
S_{i}-I_{i t}, & \text { if } I_{i t} \leq s_{i} \text { and } Q R_{i t}=0 \\
S_{i}-I_{i t}-Q R_{i t}, & \text { if } I_{i t} \leq s_{i} \text { and } Q R_{i t}>0 \\
\text { otherwise }
\end{array}\right. \\
0, \quad T Q=\sum_{t=1}^{T} \sum_{i=1}^{k} Q_{i t}
\end{gathered}
$$

$I_{t}$ is calculated by (3) where $k=6$ :

$$
I_{t}=\sum_{i=1}^{k} I_{i t}
$$


$I_{A V G}$ is calculated by (4) where $T=365$ days.

$$
I_{A V G}=\int_{0}^{T} I_{t} d t
$$

$\mathrm{TH}_{\mathrm{C}}$ is calculated by (5), where unit holding cost is assumed to be 20 percent of ordering cost plus transportation cost per product.

$$
T H C=I_{A V G} \times 20 \% \times \frac{T Q_{C}+T T_{C}}{T Q}
$$

$T L S_{C}$ is calculated by (6):

$$
T L S_{C}=\left(\sum_{i=1}^{k} \sum_{t=1}^{T} L S_{i t}\right) \times L S_{C}
$$

$T Q_{C}$ is calculated by (7):

$$
T Q_{C}=\left(\sum_{i=1}^{k} \sum_{t=1}^{T} Q_{i t}\right) \times C_{O}
$$

$n_{i t}$ is calculated by (8):

$$
n_{i t}=\frac{Q_{i t}}{C_{T}}, \text { nit } \in \text { integer }
$$

$T T_{C}$ is calculated by (9):

$$
T T_{C}=\left(\sum_{i=1}^{k} \sum_{t=1}^{T} n_{i t}\right) \times T_{C}
$$

TIS $_{C}$ is computed by (10):

$$
T I S_{C}=\sum_{t=0}^{T} \sum_{j \neq i}^{k} \sum_{i=1}^{k} L_{j i t} \times I S_{j i}
$$

As a result, total network cost is cost calculated by (11):

$$
T C=T L S_{C}+T Q_{C}+T T_{C}+T I S_{C}+T H_{C}
$$

$F L_{i}$ is computed by (12):

$$
F L_{i}=1-\frac{\sum_{t=1}^{T} L S_{i t}}{T D_{i}}
$$

We explain how inventory share implementations take place in the pre-defined policies in the following section, Section 3.4.

\subsection{Inventory Share Policies}

We apply the inventory share procedure when arriving order cannot be fully met by the store. Figure 4 shows the lateral inventory share implementation flow chart regardless of the considered policy. According to that, the first existing inventory is sent to the demand point. However, if there is remaining demand that could not be met by the store, then lateral inventory share may take place based on the pre-defined policy. Note that except for the inventory share policy implementations, in an effort to measure how lateral inventory share applications affect the system performance, we also apply a non-inventory share policy. Figure 5 shows the flow chart of the system with no inventory share application.

In Figure 6 , we show the flow chart of the $(s, S)$ inventory control policy. According to that, inventory levels are tracked in real-time, and if the current inventory level is less than or equal to the desired re-order point, then the $Q_{i t}$ amount is calculated by (1). That amount of order is placed from the main depot. 


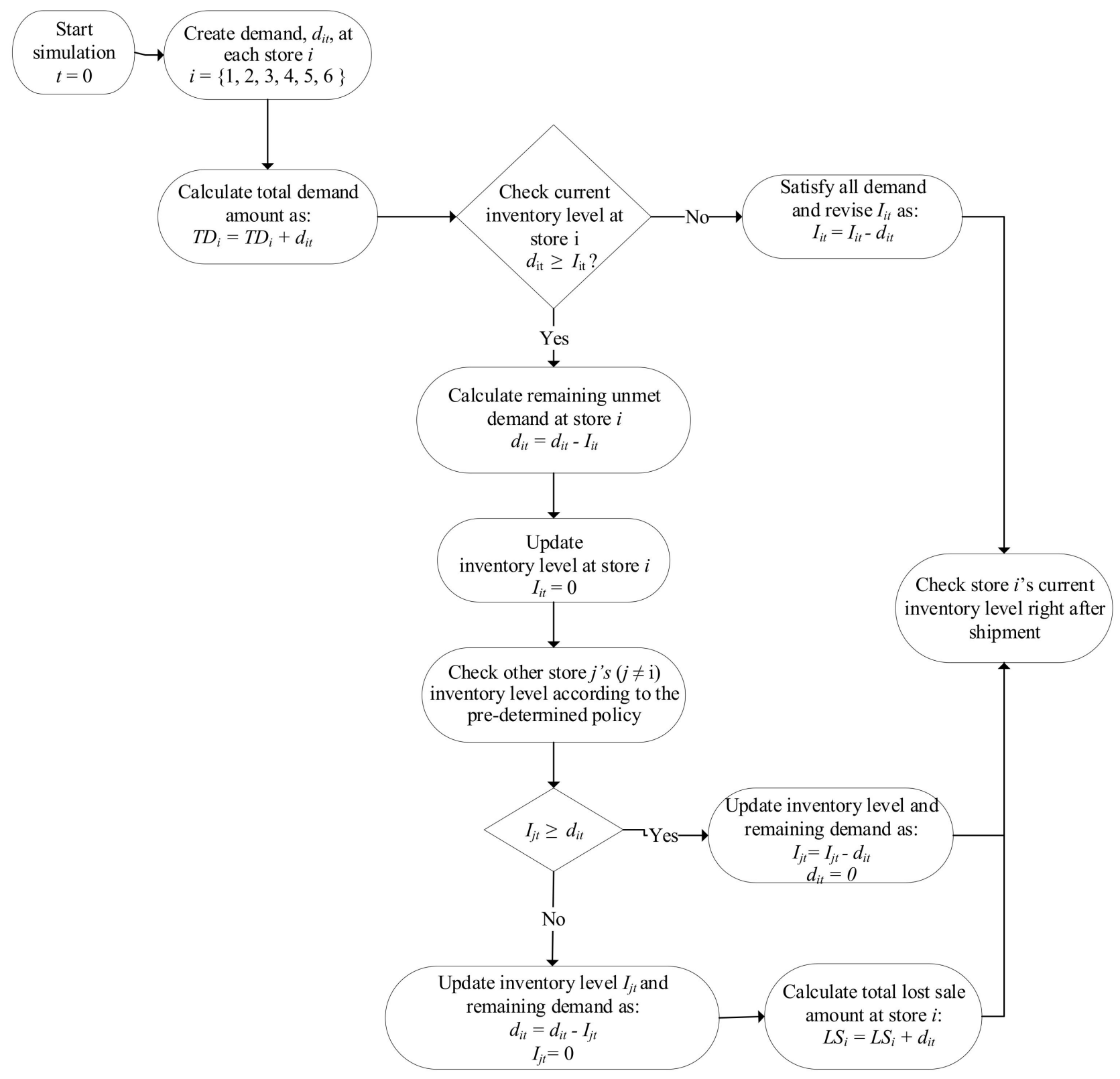

Figure 4. Simulation model flow-chart with lateral inventory share. 


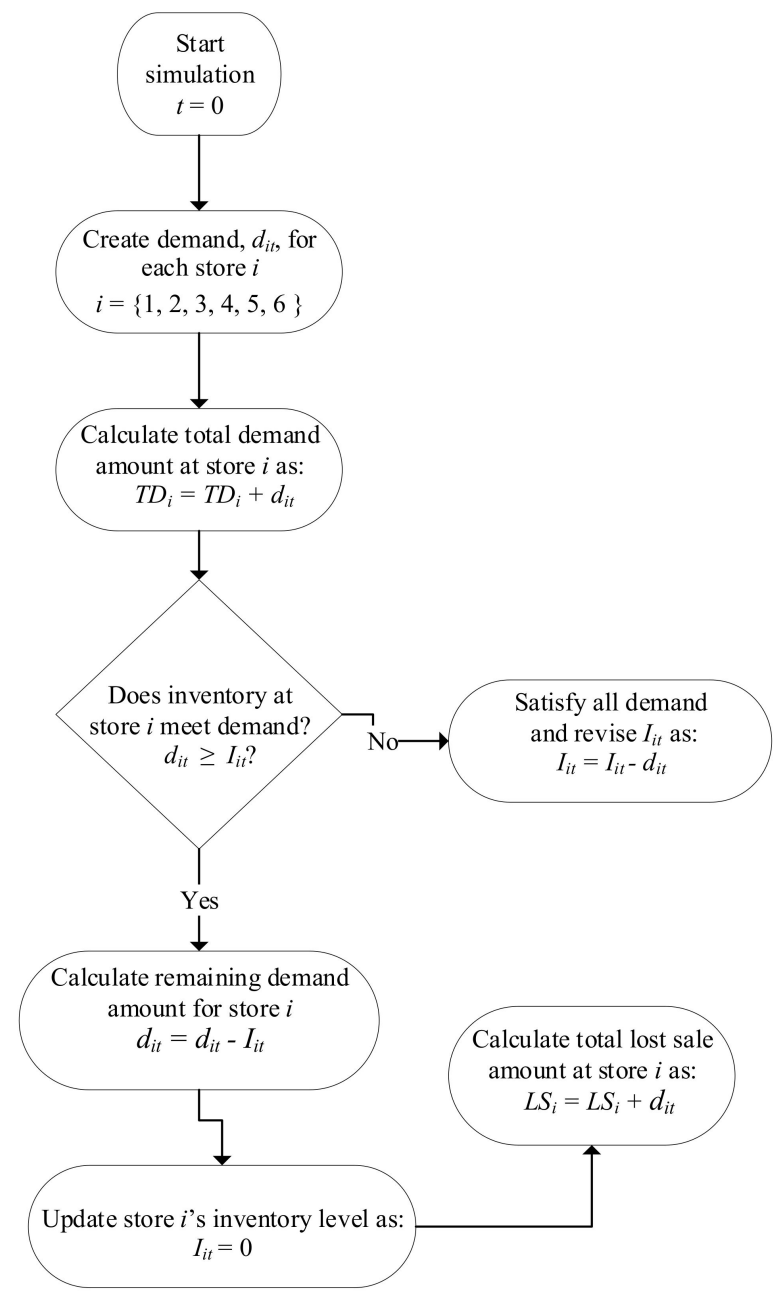

Figure 5. Simulation model flow-chart with no lateral inventory share.

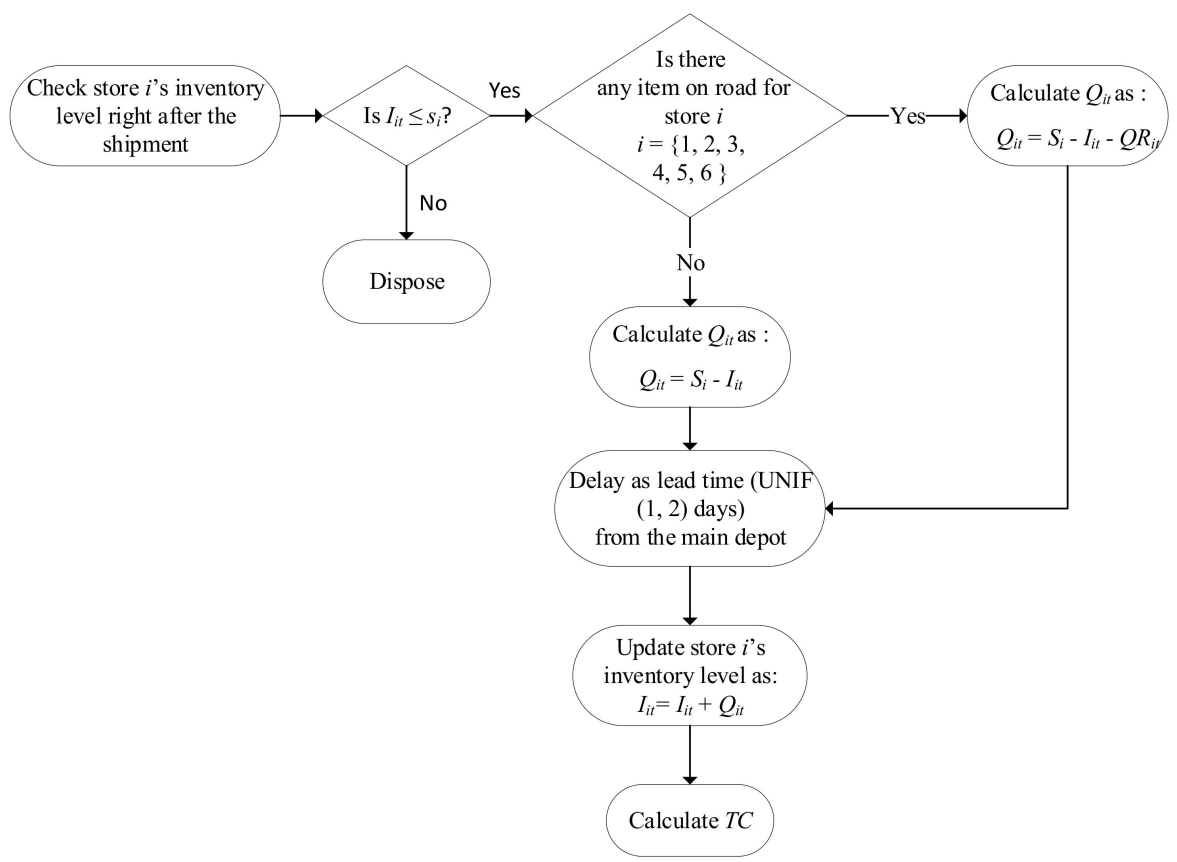

Figure 6. Replenishment policy. 
In Section 3.4.1, we introduce the developed inventory share policies.

\subsubsection{Inventory Share Policy 1}

This policy is developed for online stores. In this policy, if the demand for an online store $i$ cannot be fully met from its store, the remaining demand is tended to be met from its offline store. If there is not enough amount of products in the offline store, then the existing ones are sent from that offline store and the remaining amount is met from other online stores in the order of having the largest amount of inventory.

After all the lateral inventory shares are completed, if still there is a demand that could not be met, then that amount is considered to be a lost sale. Figure 7 shows the connectedness condition of online and offline stores under this policy.

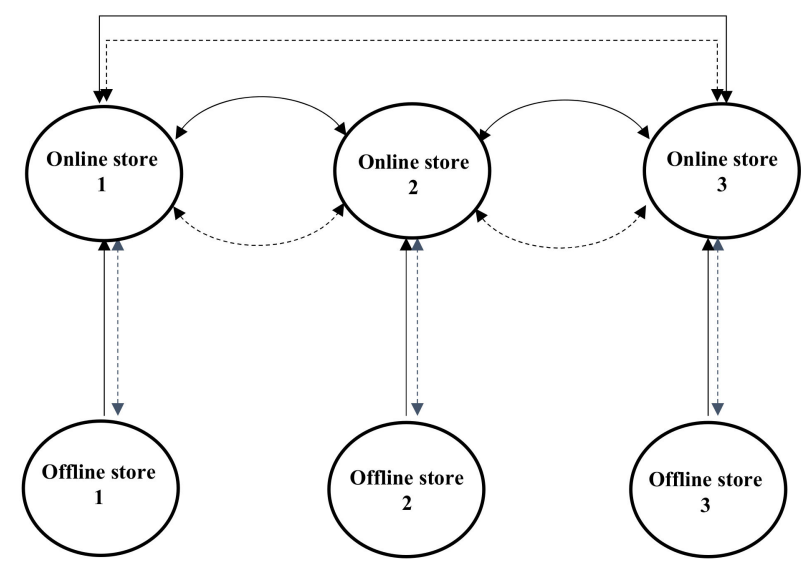

Figure 7. Connectedness level between stores under Policy 1 (Source: Authors).

\subsubsection{Inventory Share Policy 2}

This policy is also developed for online stores and it works as in Policy 1. However, different from Policy 1 here, we do not allow the online stores' inventory levels to drop below their re-order levels.

\subsubsection{Inventory Share Policy 3}

This policy is also developed for online stores, and it works in Policy 1. However, when inventory share starts to take place in online stores, the remaining demand tends to be met proportionally from the online stores. Namely, depending on the existing inventory levels, online stores share their inventories. To provide more details about this policy, we present its pseudo-codes in Figure 8. 


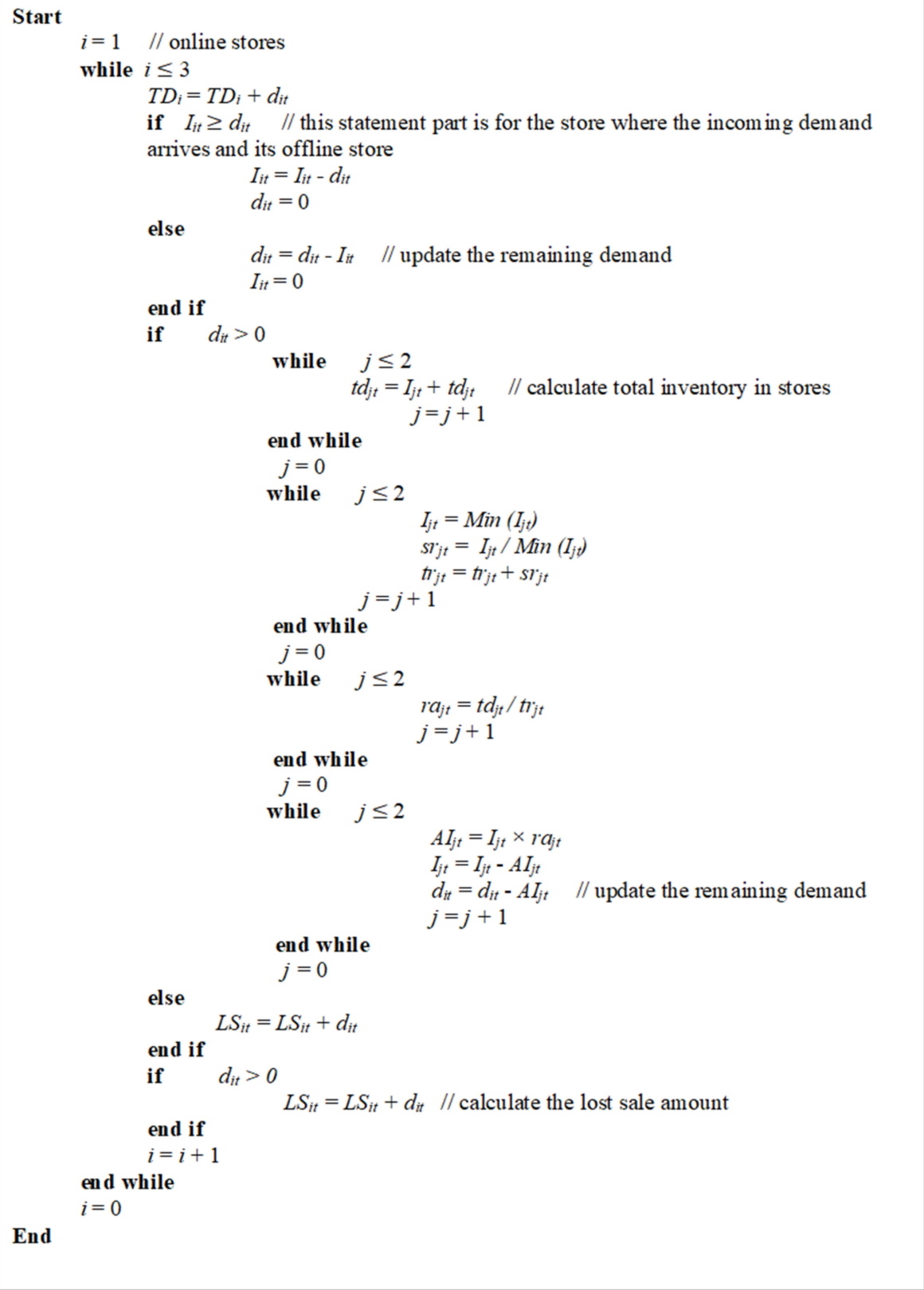

Figure 8. Pseudo-codes of Policy 3.

\subsubsection{Inventory Share Policy 4}

This policy is determined to meet the demand for offline stores. The incoming demand to the offline store $i$ is tried to be met by that offline store. If demand cannot be fully met, due to the offline customer attribute, we assume that the customer accepts to meet its demand from other stores with $75 \%$ probability. First, the same company's online store is checked, and the online store sends the required amount from its existing inventory. If all the remaining amount cannot be fully met, then the updated remaining amount becomes a lost sale. Figure 9 shows the connectedness level of online and offline stores under this policy. 

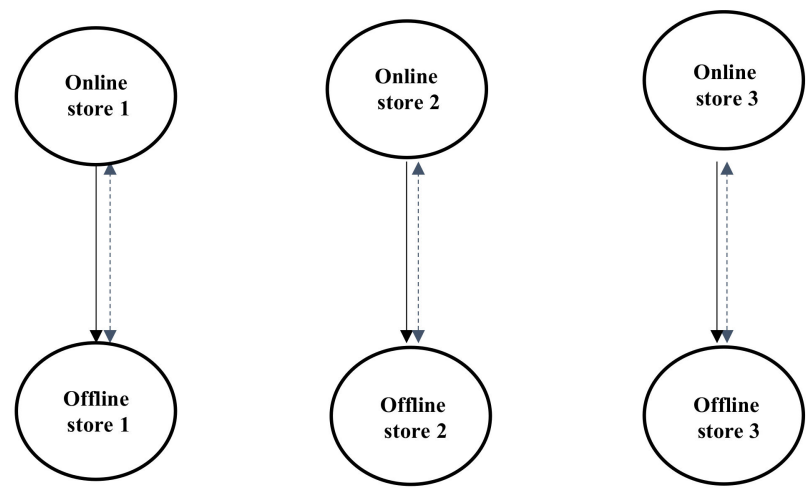

Figure 9. Connectedness level between stores for Policy 4 (Source: Authors).

\subsubsection{Inventory Share Policy 5}

This policy is also developed for offline stores. This policy works as in Policy 4 . However, the unmet amount of demand is tended to be met starting from the online stores with the highest inventory levels. Figure 10 shows the connectedness conditions of online and offline stores of this policy.

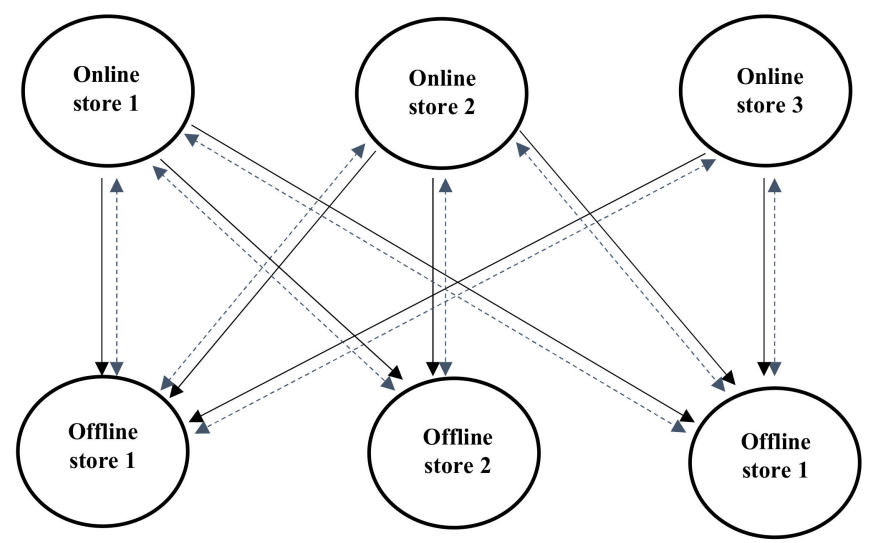

Figure 10. The connection between depots for online policy 5 (Source: Authors).

\subsubsection{Non-Inventory Share Policy 6}

In this policy, no lateral inventory share is applied. The demand can only be met by its own store of arriving demand. Inventory share from other stores is not allowed. The unfulfilled demand becomes a lost sale.

\subsection{OptQuest Optimization}

We optimize the $(s, S)$ values of stores under each inventory share policy. We have a combination of six inventory share policies plus one non-inventory share policy. There are six $(s, S)$ decision variable combinations. Consequently, we complete optimization for seven simulated policies.

OptQuest is used to optimize the $(s, S)$ values for all online and offline stores. OptQuest is a tool that improves the analysis capability of the Arena software by allowing the search for optimal results of the simulation models. In the OptQuest tool, it is necessary to enter the control values, run the software, and then enter the new control values again to find the optimal results. Thanks to this tool, the the search required to find the optimal results takes place automatically. The OptQuest tool combines three different metaheuristics approaches: Tabu search, neural networks, and scatter search [39]. This tool system performs the search for optimal results depending on the entered control variables, constraints, and objective function. The low value, suggested value, and upper value are entered into the tool by the 
user, and the search begins at the suggested value. According to the constraint specified in the objective function, the minimum or maximum result is searched.

\section{Results}

In the studied omni-channel system, there are online and offline stores for three companies at the same echelon. There is a main warehouse in the upper echelon, providing products for the stores. In this study, a total of seven models are modelled in Arena 16.0 commercial software. Decision variables, the $(s, S)$ values, are optimized by the OptQuest tool. For sensitivity analysis, seven models are run at three different lost sales per product cost scenarios $(\$ 5, \$ 10, \$ 20)$. Figure 11 shows a snapshot from the OptQuest run. The objective function and the constraints entered in OptQuest tool are shown by (13)-(16).

Minimize TC

$$
\begin{gathered}
\text { s.t. } F L_{i} \geq 0.95, \forall i \\
S_{i} \leq 200, i=\{4,5,6\} \\
s_{i}<S_{i}, \forall i
\end{gathered}
$$

\begin{tabular}{|c|c|c|}
\hline \multicolumn{3}{|r|}{ Constraints Summary } \\
\hline Name & Type & Expression \\
\hline CSL & Nonlinear & [Total_losts_sales] / [Total_demand] $<=0.05$ \\
\hline$s<S 6$ & Linear & {$[s s[6]]<\left[S \_\right.$Inventory[6]] } \\
\hline$s<S 5$ & Linear & {$[$ ss:[5]]<[S_Inventory[5]] } \\
\hline$s<S 4$ & Linear & {$[$ ss[4]] < [S_Inventory[4]] } \\
\hline$s<S 3$ & Linear & {$[s s[3]]<[S$ _nnventory[3] } \\
\hline$s<\$ 2$ & Linear & {$[$ ss[2]] $<[$ S_Inventory [2]] } \\
\hline$s<S 1$ & Linear & [ss[1]]< [S_Inventory[1]] \\
\hline
\end{tabular}

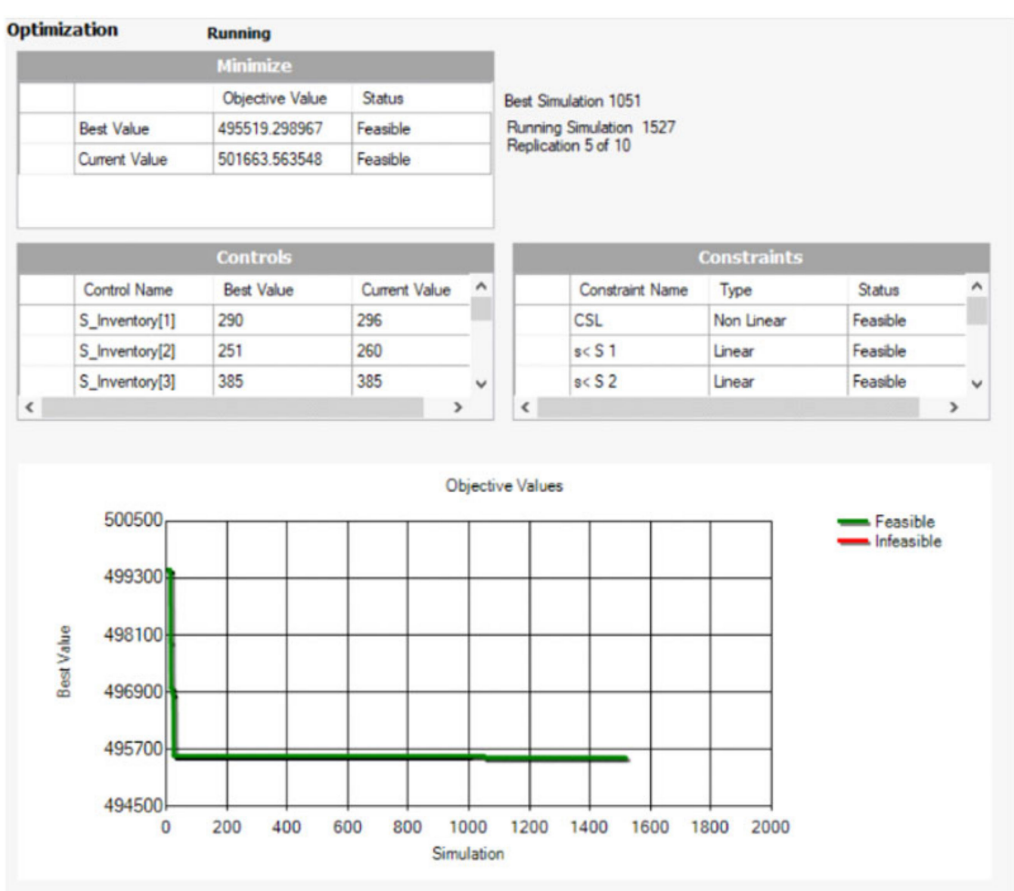

(a)

\begin{tabular}{|c|c|c|c|c|c|c|c|c|}
\hline \multirow[b]{2}{*}{ Included } & \multirow[b]{2}{*}{ Category } & \multicolumn{7}{|c|}{ Controls Summary } \\
\hline & & Name & Element Type & Type & Low Bound & Suggested Value & High Bound & Step \\
\hline$\square$ & User Specified & S_Inventory[1] & Variable & Discrete & 280 & 290 & 295 & 1 \\
\hline 口 & User Specified & S_Inventory[2] & Variable & Discrete & 246 & 251 & 256 & 1 \\
\hline$\square$ & User Specified & S_Inventory [3] & Variable & Discrete & 380 & 385 & 390 & 1 \\
\hline$\square$ & User Specified & S_Inventory [4] & Variable & Discrete & 145 & 150 & 155 & 1 \\
\hline$\square$ & User Specified & S_Inventory[5] & Variable & Discrete & 153 & 158 & 163 & 1 \\
\hline 口 & User Specified & S_Inventory[6] & Variable & Discrete & 184 & 189 & 194 & 1 \\
\hline$\square$ & User Specified & ss[1] & Variable & Discrete & 126 & 131 & 136 & 1 \\
\hline$\square$ & User Specified & $\mathrm{ss}[2]$ & Variable & Discrete & 107 & 112 & 117 & 1 \\
\hline$\square$ & User Specified & ss[3] & Variable & Discrete & 149 & 154 & 159 & 1 \\
\hline$\square$ & User Specified & ss[4] & Variable & Discrete & 86 & 91 & 96 & 1 \\
\hline$\square$ & User Specified & ss[5] & Variable & Discrete & 82 & 87 & 92 & 1 \\
\hline$\square$ & User Specified & ss[6] & Variable & Discrete & 117 & 122 & 127 & 1 \\
\hline
\end{tabular}

(b)

(c)

Figure 11. OptQuest screenshots: (a) Visualized $(s, S)$ values for results; $(\mathbf{b})$ part where the specified constraints are defined; (c) control part of the decision variables (Source: Authors). 
Tables 1-3 provide the optimized $(s, S)$ results by OptQuest. Results are presented based on the considered lost sale cost per product $\left(L S_{C}\right)$ scenarios. Table 1 shows the results when $L S_{C}=\$ 5$.

Table 1. Optimal $(s, S)$ values when lost sale cost $\left(L S_{C}\right)=\$ 5$.

\begin{tabular}{ccccccc}
\hline & $\begin{array}{c}\text { Online } \\
\text { Depot 1 }\end{array}$ & $\begin{array}{c}\text { Online } \\
\text { Depot 2 }\end{array}$ & $\begin{array}{c}\text { Online } \\
\text { Depot 3 }\end{array}$ & $\begin{array}{c}\text { Offline } \\
\text { Depot 1 }\end{array}$ & $\begin{array}{c}\text { Offline } \\
\text { Depot 2 }\end{array}$ & $\begin{array}{c}\text { Offline } \\
\text { Depot 3 }\end{array}$ \\
\hline Policy & $\left(s_{1}, s_{1}\right)$ & $\left(s_{2}, S_{2}\right)$ & $\left(s_{3}, s_{3}\right)$ & $\left(s_{4}, s_{4}\right)$ & $\left(s_{5}, s_{5}\right)$ & $\left(s_{6}, S_{6}\right)$ \\
$1 \& 4$ & $(134,370)$ & $(69,214)$ & $(142,390)$ & $(105,168)$ & $(90,176)$ & $(106,180)$ \\
$2 \& 4$ & $(116,353)$ & $(87,295)$ & $(115,401)$ & $(108,176)$ & $(98,160)$ & $(108,178)$ \\
$3 \& 4$ & $(121,334)$ & $(65,283)$ & $(200,464)$ & $(115,174)$ & $(69,144)$ & $(138,191)$ \\
$1 \& 5$ & $(70,299)$ & $(102,248)$ & $(170,334)$ & $(92,166)$ & $(77,131)$ & $(68,198)$ \\
$2 \& 5$ & $(120,307)$ & $(106,341)$ & $(108,376)$ & $(101,169)$ & $(86,163)$ & $(105,157)$ \\
$3 \& 5$ & $(110,365)$ & $(86,257)$ & $(155,468)$ & $(101,185)$ & $(84,156)$ & $(103,178)$ \\
6 & $(253,355)$ & $(200,292)$ & $(299,430)$ & $(130,174)$ & $(127,181)$ & $(147,188)$ \\
\hline
\end{tabular}

Table 2. Optimal $(s, S)$ values when LSC $=\$ 10$.

\begin{tabular}{ccccccc}
\hline & $\begin{array}{c}\text { Online } \\
\text { Depot 1 }\end{array}$ & $\begin{array}{c}\text { Online } \\
\text { Depot 2 }\end{array}$ & $\begin{array}{c}\text { Online } \\
\text { Depot 3 }\end{array}$ & $\begin{array}{c}\text { Offline } \\
\text { Depot 1 }\end{array}$ & $\begin{array}{c}\text { Offline } \\
\text { Depot 2 }\end{array}$ & $\begin{array}{c}\text { Offline } \\
\text { Depot 3 }\end{array}$ \\
\hline Policy & $\left(s_{1}, S_{1}\right)$ & $\left(s_{2}, S_{2}\right)$ & $\left(s_{3}, s_{3}\right)$ & $\left(s_{4}, S_{4}\right)$ & $\left(s_{5}, S_{5}\right)$ & $\left(s_{6}, S_{6}\right)$ \\
$1 \& 4$ & $(114,388)$ & $(100,284)$ & $(122,415)$ & $(99,172)$ & $(90,153)$ & $(120,199)$ \\
$2 \& 4$ & $(105,345)$ & $(133,377)$ & $(138,395)$ & $(102,169)$ & $(91,163)$ & $(114,185)$ \\
$3 \& 4$ & $(136,382)$ & $(40,227)$ & $(203,522)$ & $(139,197)$ & $(59,116)$ & $(114,173)$ \\
$1 \& 5$ & $(132,291)$ & $(114,255)$ & $(150,388)$ & $(94,153)$ & $(84,156)$ & $(125,184)$ \\
$2 \& 5$ & $(91,334)$ & $(97,350)$ & $(141,384)$ & $(100,171)$ & $(70,136)$ & $(125,191)$ \\
$3 \& 5$ & $(155,360)$ & $(108,254)$ & $(229,472)$ & $(95,175)$ & $(80,155)$ & $(101,190)$ \\
6 & $(274,359)$ & $(250,315)$ & $(311,427)$ & $(128,175)$ & $(135,173)$ & $(150,192)$ \\
\hline
\end{tabular}

Table 3. Optimal $(s, S)$ values when $L S_{C}=\$ 20$.

\begin{tabular}{ccccccc}
\hline & $\begin{array}{c}\text { Online } \\
\text { Depot 1 }\end{array}$ & $\begin{array}{c}\text { Online } \\
\text { Depot 2 }\end{array}$ & $\begin{array}{c}\text { Online } \\
\text { Depot 3 }\end{array}$ & $\begin{array}{c}\text { Offline } \\
\text { Depot 1 }\end{array}$ & $\begin{array}{c}\text { Offline } \\
\text { Depot 2 }\end{array}$ & $\begin{array}{c}\text { Offline } \\
\text { Depot 3 }\end{array}$ \\
\hline Policy & $\left(s_{1}, S_{1}\right)$ & $\left(s_{2}, S_{2}\right)$ & $\left(s_{3}, S_{3}\right)$ & $\left(s_{4}, S_{4}\right)$ & $\left(s_{5}, S_{5}\right)$ & $\left(s_{6}, S_{6}\right)$ \\
$1 \& 4$ & $(177,356)$ & $(128,271)$ & $(152,419)$ & $(110,173)$ & $(109,181)$ & $(123,188)$ \\
$2 \& 4$ & $(145,441)$ & $(77,328)$ & $(171,435)$ & $(125,183)$ & $(99,164)$ & $(122,181)$ \\
$3 \& 4$ & $(158,415)$ & $(148,293)$ & $(211,463)$ & $(100,171)$ & $(115,188)$ & $(139,196)$ \\
$1 \& 5$ & $(138,393)$ & $(137,275)$ & $(142,363)$ & $(108,170)$ & $(123,193)$ & $(144,199)$ \\
$2 \& 5$ & $(100,367)$ & $(110,397)$ & $(167,419)$ & $(121,193)$ & $(89,162)$ & $(122,172)$ \\
$3 \& 5$ & $(146,392)$ & $(81,339)$ & $(224,477)$ & $(77,140)$ & $(101,172)$ & $(141,197)$ \\
6 & $(285,404)$ & $(250,371)$ & $(314,469)$ & $(131,198)$ & $(145,168)$ & $(148,197)$ \\
\hline
\end{tabular}

The optimal network total costs, related outputs, and their half-width values at $95 \%$ levels are illustrated in Tables $4-6$ based on the $L S_{C}$ values. These tables show optimal results with their half widths at $95 \%$ confidence intervals for all lost sale per unit cost. 
Table 4. Optimal cost results when $L S_{C}=\$ 5$.

\begin{tabular}{ccccccc}
\hline Policy & $\begin{array}{c}\text { Total Lost Sale } \\
\text { Cost }\end{array}$ & $\begin{array}{c}\text { Total } \\
\text { Transportation } \\
\text { Cost }\end{array}$ & $\begin{array}{c}\text { Total Holding } \\
\text { Cost }\end{array}$ & $\begin{array}{c}\text { Total Inventory } \\
\text { Share } \\
\text { Cost }\end{array}$ & $\begin{array}{c}\text { Total Ordering } \\
\text { Cost }\end{array}$ & Total Cost \\
\hline $1 \& 4$ & $17,280 \pm 2950.8$ & $140,410 \pm 2624.4$ & $141,820 \pm 2209.7$ & $19,649 \pm 1612.3$ & $167,430 \pm 3293.9$ & $486,590 \pm 7113.9$ \\
$2 \& 4$ & $19,586 \pm 2207.8$ & $141,180 \pm 2968.5$ & $151,190 \pm 2181.5$ & $17,523 \pm 1118.4$ & $167,850 \pm 3602.8$ & $497,330 \pm 3602.8$ \\
$3 \& 4$ & $23,006 \pm 2589.7$ & $144,440 \pm 2434.4$ & $155,420 \pm 2595.6$ & $16,274 \pm 1379.4$ & $169,860 \pm 2967.2$ & $509,000 \pm 6539.3$ \\
$1 \& 5$ & $15,435 \pm 1444.3$ & $140,770 \pm 2606.2$ & $122,160 \pm 1766.2$ & $28,880 \pm 1448.9$ & $168,470 \pm 3097.7$ & $475,720 \pm 5963.2$ \\
$2 \& 5$ & $18,327 \pm 2412.5$ & $141,220 \pm 2536.5$ & $143,840 \pm 1652.7$ & $21,446 \pm 1168.6$ & $167,400 \pm 2847.3$ & $492,230 \pm 2847.3$ \\
$3 \& 5$ & $20,042 \pm 1891.4$ & $139,470 \pm 3231.3$ & $152,670 \pm 3651.9$ & $20,107 \pm 1337.9$ & $167,840 \pm 3651.9$ & $500,130 \pm 6637.7$ \\
6 & $28,356 \pm 3047.6$ & $159,000 \pm 2850.8$ & $215,570 \pm 2412.9$ & 0 & $166,900 \pm 3214.9$ & $569,830 \pm 5862.1$ \\
\hline
\end{tabular}

Table 5. Optimal cost results when $L S_{C}=\$ 10$.

\begin{tabular}{ccccccc}
\hline Policy & $\begin{array}{c}\text { Total Lost Sale } \\
\text { Cost }\end{array}$ & $\begin{array}{c}\text { Total } \\
\text { Transportation } \\
\text { Cost }\end{array}$ & $\begin{array}{c}\text { Total Holding } \\
\text { Cost }\end{array}$ & $\begin{array}{c}\text { Total Inventory } \\
\text { Share } \\
\text { Cost }\end{array}$ & $\begin{array}{c}\text { Total Ordering } \\
\text { Cost }\end{array}$ & Total Cost \\
\hline $1 \& 4$ & $29,221 \pm 3083.6$ & $141.570 \pm 2854.6$ & $156,500 \pm 2192.9$ & $17,636 \pm 1134.8$ & $167,960 \pm 3350.3$ & $512.880 \pm 7447.9$ \\
$2 \& 4$ & $38,577 \pm 4417.8$ & $137,810 \pm 2293.8$ & $158,970 \pm 2012.8$ & $16,067 \pm 1225.4$ & $167,440 \pm 2779.2$ & $518.860 \pm 7827.5$ \\
3 \& 4 & $36,948 \pm 1851.2$ & $140,540 \pm 2976.3$ & $161,400 \pm 2105.6$ & $15,674 \pm 920.05$ & $167,010 \mathrm{~s} \pm 3681.0$ & $521,570 \pm 6074.8$ \\
$1 \& 5$ & $21,976 \pm 3148.9$ & $144,540 \pm 3262.6$ & $136,030 \pm 2197.1$ & $22,936 \pm 1639.8$ & $170,040 \pm 3665.8$ & $495,520 \pm 7775.0$ \\
$2 \& 5$ & $27,022 \pm 2140.3$ & $139,590 \pm 2471.1$ & $147,100 \pm 1949.6$ & $20,839 \pm 1476.8$ & $169,250 \pm 3233.5$ & $503,800 \pm 5761.9$ \\
3 \& 5 & $28,074 \pm 3680.1$ & $144,540 \pm 2977.1$ & $159,720 \pm 2431.7$ & $16,034 \pm 1315.1$ & $169,790 \pm 3523.3$ & $518,160 \pm 7667.1$ \\
6 & $53,131 \pm 6222.0$ & $161,490 \pm 2879.1$ & $227,910 \pm 2575.6$ & 0 & $167,470 \pm 2575.6$ & $610,000 \pm 8469.3$ \\
\hline
\end{tabular}

Table 6. Optimal cost results when $L S_{C}=\$ 20$.

\begin{tabular}{|c|c|c|c|c|c|c|}
\hline Policy & $\begin{array}{c}\text { Total Lost Sale } \\
\text { Cost }\end{array}$ & $\begin{array}{c}\text { Total } \\
\text { Transportation } \\
\text { Cost }\end{array}$ & $\begin{array}{c}\text { Total Holding } \\
\text { Cost }\end{array}$ & $\begin{array}{c}\text { Total Inventory } \\
\text { Share } \\
\text { Cost }\end{array}$ & $\begin{array}{c}\text { Total Ordering } \\
\text { Cost }\end{array}$ & Total Cost \\
\hline $1 \& 4$ & $41,576 \pm 5195.3$ & $143,580 \pm 2538.4$ & $162,200 \pm 2432.8$ & $15,234 \pm 1130.0$ & $170,490 \pm 3253.9$ & $533,080 \pm 7668.3$ \\
\hline $2 \& 4$ & $49,086 \pm 4256.1$ & $141,200 \pm 2800.1$ & $173,620 \pm 2052.8$ & $14,161 \pm 1312.2$ & $170,250 \pm 3586.2$ & $548,320 \pm 8717.6$ \\
\hline $3 \& 4$ & $50,200 \pm 10,586.0$ & $140,940 \pm 1995.2$ & $182,040 \pm 2128.6$ & $10,283 \pm 1057.8$ & $170,060 \pm 2710.0$ & $553,530 \pm 12.949 .0$ \\
\hline $1 \& 5$ & $25,430 \pm 5172.7$ & $144,810 \pm 3359.5$ & $162,270 \pm 2277.3$ & $17,724 \pm 1543.9$ & $171,890 \pm 4179.6$ & $522,130 \pm 8956.2$ \\
\hline $2 \& 5$ & $39,930 \pm 7014.1$ & $142,430 \pm 2772.2$ & $169,390 \pm 2037.4$ & $16,796 \pm 618.23$ & $170,000 \pm 3177.4$ & $538,550 \pm 11,185.0$ \\
\hline $3 \& 5$ & $41,654 \pm 7692.9$ & $141,280 \pm 3756.3$ & $171,830 \pm 3029.3$ & $14,647 \pm 1137.3$ & $171,330 \pm 4703.5$ & $540,740 \pm 12,726.0$ \\
\hline 6 & $83,668 \pm 8498.9$ & $159,560 \pm 2849.5$ & $247,470 \pm 2445.9$ & 0 & $169,080 \pm 3231.0$ & $659,780 \pm 11,054.0$ \\
\hline
\end{tabular}

Tables 7-9 provide the other significant output variables from the systems at optimal total cost results.

Table 7. System variable results $L S_{C}=\$ 5$.

\begin{tabular}{ccccccc}
\hline Policy & $\begin{array}{c}\text { Lateral } \\
\text { Inventory Share } \\
\text { Frequency }\end{array}$ & $\begin{array}{c}\text { Amount of } \\
\text { Product Shared by } \\
\text { Lateral Inventory } \\
\text { Share }\end{array}$ & $\begin{array}{c}\text { Total Lost Sale } \\
\text { Amount }\end{array}$ & $\begin{array}{c}\text { Frequency of } \\
\text { Orders Given } \\
\text { to the Main } \\
\text { Depot }\end{array}$ & $\begin{array}{c}\text { Total Number } \\
\text { of Trucks Sent } \\
\text { from the Main } \\
\text { Depot }\end{array}$ & $\begin{array}{c}\text { FL } \\
\text { Det }\end{array}$ \\
\hline $1 \& 4$ & $478.10 \pm 31.546$ & $18,127 \pm 1417.0$ & $3456.1 \pm 590.17$ & $839.10 \pm 17.461$ & $1404.1 \pm 26.244$ & $0.97004 \pm 0.00485$ \\
$2 \& 4$ & $419.40 \pm 20.838$ & $15,885 \pm 987.49$ & $3917.3 \pm 441.57$ & $841.80 \pm 17.242$ & $1411.8 \pm 29.625$ & $0.96622 \pm 0.00320$ \\
$3 \& 4$ & $458.70 \pm 38.613$ & $15,731 \pm 13.882$ & $4601.2 \pm 517.95$ & $846.00 \pm 13.882$ & $1444.4 \pm 24.344$ & $0.96071 \pm 0.00388$ \\
$1 \&$ \& & $644.40 \pm 29.487$ & $24,540 \pm 1112.4$ & $3087.1 \pm 288.97$ & $850.10 \pm 15.723$ & $1407.7 \pm 26.062$ & $0.97327 \pm 0.00224$ \\
$2 \& 5$ & $493.30 \pm 28.606$ & $17,905 \pm 964.74$ & $3665.5 \pm 482.50$ & $868.60 \pm 16.921$ & $1412.2 \pm 25.365$ & $0.96881 \pm 0.00385$ \\
$3 \& 5$ & $512.60 \pm 35.872$ & $18,187 \pm 1287.2$ & $4008.5 \pm 378.29$ & $771.80 \pm 17.462$ & $1394.7 \pm 32.313$ & $0.96511 \pm 0.00310$ \\
6 & 0 & 0 & $5671.3 \pm 609.52$ & $1215.5 \pm 26.143$ & $1590.0 \pm 28.508$ & $0.95157 \pm 0.00476$ \\
\hline
\end{tabular}


Table 8. System variable results $L S_{C}=\$ 10$.

\begin{tabular}{ccccccc}
\hline Policy & $\begin{array}{c}\text { Lateral } \\
\text { Inventory Share } \\
\text { Frequency }\end{array}$ & $\begin{array}{c}\text { Amount of } \\
\text { Product Shared by } \\
\text { Lateral Inventory } \\
\text { Share }\end{array}$ & $\begin{array}{c}\text { Total Lost Sale } \\
\text { Amount }\end{array}$ & $\begin{array}{c}\text { Frequency of } \\
\text { Orders Given } \\
\text { to the Main } \\
\text { Depot }\end{array}$ & $\begin{array}{c}\text { Total Number } \\
\text { of Trucks Sent } \\
\text { from the Main } \\
\text { Depot }\end{array}$ & $\begin{array}{c}\text { FL } \\
\text { Depot }\end{array}$ \\
\hline $1 \& 4$ & $417.50 \pm 23.650$ & $16,343 \pm 997.36$ & $2922.1 \pm 308.36$ & $801.30 \pm 12.657$ & $1415.7 \pm 28.546$ & $0.97462 \pm 0.00236$ \\
$2 \& 4$ & $338.50 \pm 23.279$ & $14,431 \pm 18.826$ & $3857.7 \pm 441.78$ & $807.60 \pm 16.826$ & $1378.1 \pm 22.938$ & $0.96664 \pm 0.00344$ \\
$3 \& 4$ & $475.70 \pm 25.981$ & $15,446 \pm 949.43$ & $3694.8 \pm 185.12$ & $862.30 \pm 14.894$ & $1405.4 \pm 29.763$ & $0.96773 \pm 0.00163$ \\
$1 \& 5$ & $528.10 \pm 28.765$ & $19,764 \pm 1425.9$ & $2196.6 \pm 314.89$ & $958.70 \pm 15.902$ & $1445.4 \pm 32.626$ & $0.98100 \pm 0.00256$ \\
$2 \& 5$ & $476.70 \pm 29.950$ & $17,469 \pm 1246.5$ & $2702.2 \pm 214.03$ & $822.00 \pm 15.061$ & $1395.9 \pm 24.711$ & $0.97660 \pm 0.00181$ \\
$3 \& 5$ & $432.70 \pm 29.450$ & $13,882 \pm 1147.8$ & $2807.4 \pm 368.01$ & $799.50 \pm 15.271$ & $1445.4 \pm 29.771$ & $0.97572 \pm 0.00297$ \\
6 & 0 & 0 & $5313.1 \pm 622.20$ & $1344.8 \pm 25.807$ & $1614.9 \pm 28.791$ & $0.95466 \pm 0.00473$ \\
\hline
\end{tabular}

Table 9. System variable results $L S_{C}=\$ 20$.

\begin{tabular}{ccccccc}
\hline Policy & $\begin{array}{c}\text { Lateral } \\
\text { Inventory Share } \\
\text { Frequency }\end{array}$ & $\begin{array}{c}\text { Amount of } \\
\text { Product Shared by } \\
\text { Lateral Inventory } \\
\text { Share }\end{array}$ & $\begin{array}{c}\text { Total Lost Sale } \\
\text { Amount }\end{array}$ & $\begin{array}{c}\text { Frequency of } \\
\text { Orders Given } \\
\text { to the Main } \\
\text { Depot }\end{array}$ & $\begin{array}{c}\text { Total Number } \\
\text { of Trucks Sent } \\
\text { from the Main } \\
\text { Depot }\end{array}$ & $\begin{array}{c}\text { FL } \\
\text { Det }\end{array}$ \\
\hline $1 \& 4$ & $361.10 \pm 23.816$ & $14,149 \pm 962.23$ & $2078.8 \pm 259.79$ & $912.90 \pm 17.019$ & $1435.8 \pm 25.854$ & $0.98207 \pm 0.00211$ \\
$2 \& 4$ & $345.10 \pm 24.603$ & $12,843 \pm 1118.6$ & $2454.3 \pm 212.80$ & $857.70 \pm 14.886$ & $1412.0 \pm 2309.8$ & $0.97884 \pm 0.00165$ \\
$3 \& 4$ & $291.60 \pm 25.863$ & $9850 \pm 1118.4$ & $2510.0 \pm 529.30$ & $873.40 \pm 16.273$ & $1409.4 \pm 19.952$ & $0.97834 \pm 0.00426$ \\
$1 \&$ \& & $400.80 \pm 27.491$ & $16,081 \pm 1338.5$ & $1271.5 \pm 258.63$ & $947.10 \pm 19.50$ & $1448.1 \pm 33.595$ & $0.98902 \pm 0.00226$ \\
$2 \& 5$ & $377.50 \pm 15.610$ & $14,019 \pm 482.82$ & $1996.5 \pm 350.70$ & $846.70 \pm 18.208$ & $1424.3 \pm 27.722$ & $0.98305 \pm 0.00272$ \\
$3 \& 5$ & $390.30 \pm 27.578$ & $12,369 \pm 1024.4$ & $2082.7 \pm 398.14$ & $844.00 \pm 17.592$ & $1412.8 \pm 37.563$ & $0.98211 \pm 0.00311$ \\
6 & 0 & 0 & $5671.3 \pm 424.94$ & $1189.9 \pm 23.820$ & $1595.6 \pm 28.495$ & $0.95157 \pm 0.00326$ \\
\hline
\end{tabular}

The interpretation of the results is summarized in Section 5.

\section{Discussion}

Results from the OptQuest runs are also summarized in Figures 10-12. According to the results, any lateral inventory share policy produces better total network costs than non-lateral inventory share policy. This also echoes the findings of previous works of $[21,27,36,37]$. This is also true under different lost sale per product cost $\left(L S_{C}\right)$ scenario. However, when $L S_{C}$ increases, the gap between non-lateral share application cost result and the worst result from a lateral inventory share policy gets larger. This means that when lost sale unit cost increases, implementation of lateral inventory share policy works better than under the low lost sale unit cost case.

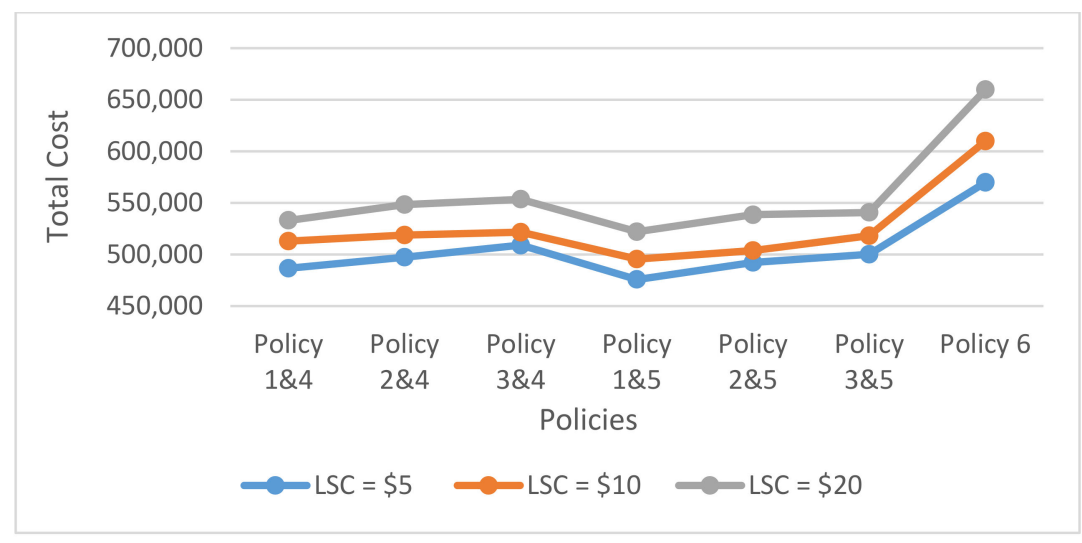

Figure 12. Optimal total costs versus policies based on $L S_{C}$ values. 
With the lateral inventory share implementations, it is observed that the amount of holding cost tends to decrease. This is probably because that inventory share of stores helps to carry low inventory in the network. This would also contribute to the circular economy concept by the decrease of material consumption as well as $\mathrm{CO}_{2}$ emission released during production.

Note that, by lateral inventory share implementation, total transportation costs, as well as the number of trucks sent from the main depot, also tend to decrease. Those would also contribute to $\mathrm{CO}_{2}$ emission reduction in the network. Other comments on key findings are summarized below:

- With the increase of $L S_{C}$, the reorder levels increase. This means that the network tends to carry more inventory.

- Lateral inventory share implementations mostly produce lower re-order levels for stores compared to non-lateral share policy.

- In general, it is observed that total holding cost increases as the $L S_{C}$ increases. This is probably because the system tries to reduce the possibility of lost sale condition by holding excess amounts of products in inventory.

- Policy $1 \& 5$ combination produces the best result among all policies. That combination focuses on the lateral share of stores having a high amount of inventories.

- With the increase of $L S_{C}, F L$ values tend to increase. This is probably because having lost sale in the system becomes much more expensive than carrying inventory in the network. So, by carrying more inventory, the $F L$ tends to increase under high $L S_{C}$ levels.

From Figure 12, the optimal total cost results based on scenarios and $L S_{C}$ values are presented by graphs. According to that figure, the least TC is obtained by Policy $1 \& 5$ under any $L S_{C}$ scenario. Besides, when $L S_{C}$ increases, $T C$ also increases. The TC gap between the same policy increases when $L S_{C}$ increases.

In Figure 13, total transportation costs based on policies are presented. According to that figure, it is observed that total transportation cost tends to decrease by any lateral inventory share implementation. This is because Policy 6, representing the non-lateral inventory share implementation, has the highest transportation cost result in all $L S_{C}$ scenarios.

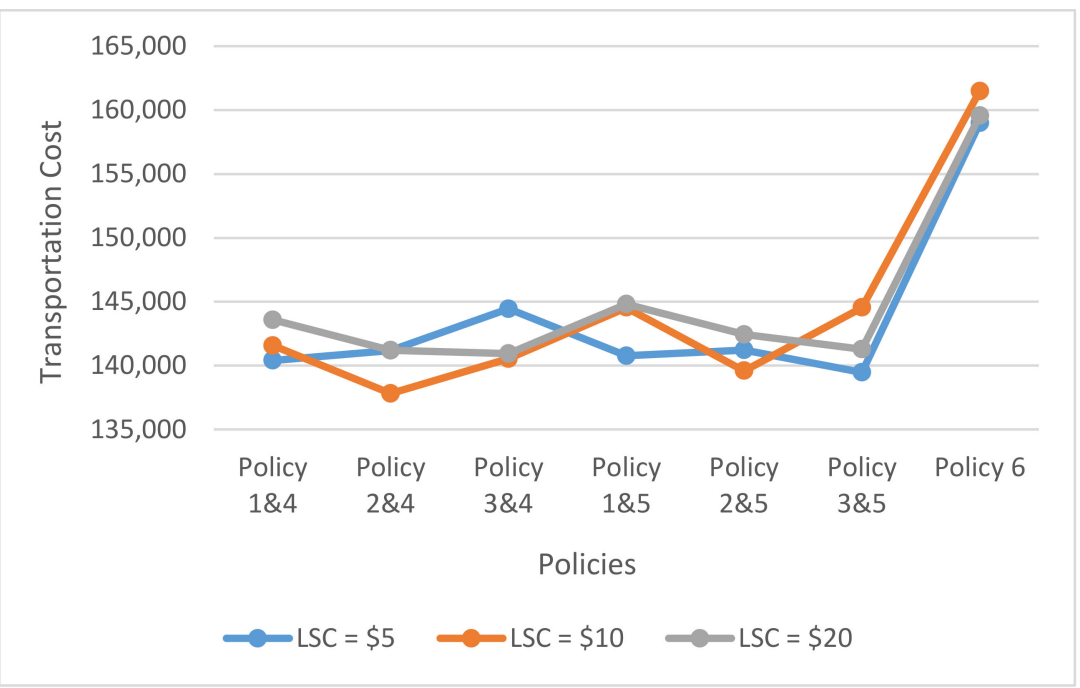

Figure 13. Total transportation cost under optimal total cost.

From Figure 14, it is observed that the least total holding cost is obtained by Policy $1 \& 5$. Moreover, when $L S_{C}$ increases, the total holding cost also increases. As mentioned, this is probably because that, to be able to provide at least $95 \%$ FL, the network tends to carry more inventory. Minimized holding cost also contributes to the circular economy and sustainability concepts by the decreased usage of materials due to the excess amount of 
production. Besides, by the decreased holding cost, we also contribute to the environment positively, by the possible release of $\mathrm{CO}_{2}$ during production and transportation through the supply chain.

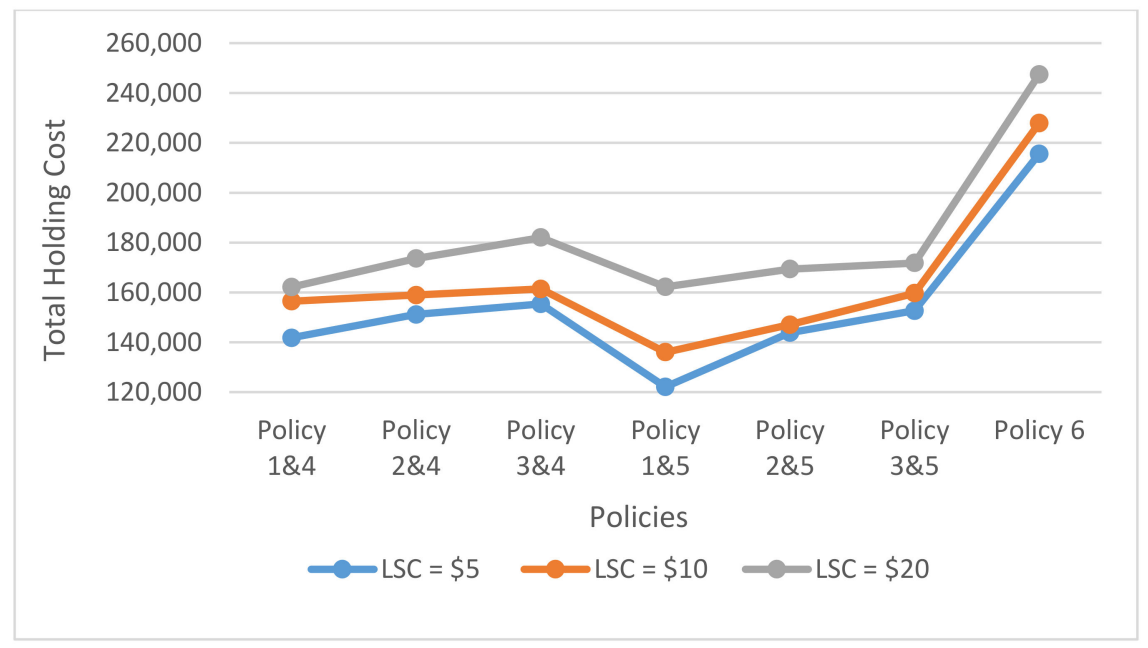

Figure 14. Total holding cost under optimal cost.

\section{Conclusions}

In this work, we study an omni-channel supply network where stages are connected to each other under an IoT environment and they can share real-time information on their inventory levels and demand amounts. By today's technological developments, it is possible to have end-to-end supply chain connections through a network. By assuming that, we apply lateral inventory share policies in that omni-channel network so that the network becomes more cost-efficient and responsive. Specifically, we aim to find a well-designed lateral inventory share policy contributing to decreased total network cost by the decreased inventory carried in the network. Thus, we also aim to contribute to sustainability and circular economy concepts by decreased production and $\mathrm{CO}_{2}$ emissions.

We consider an $(s, S)$ inventory control policy in the network and optimize the $s, S$ levels under total cost minimization. We also repeat the optimization procedure for different lost sale unit cost cases: $\$ 5, \$ 10, \$ 20$. All scenarios are simulated in Arena commercial software and optimized by the OptQuest tool. The results at the optimal points show that the lateral inventory share performs well in all policies and lost sale per-unit costs. Considering the results, holding cost tends to decrease by lateral inventory share implementations. By that, we also contribute to sustainability and circular economy concepts.

As future works, exploration of more lateral inventory share policies can be completed, also including more stores and connectedness in the network. Besides, more sensitivity analysis under different parameter values would be worth searching. In addition, smart delivery operations, by considering that trucks, transportation amounts, product types, etc., can be tracked in real-time and they can merge the orders according to their routes or less than half truck conditions to decrease transportation costs can be explored. In addition, transportation from stores to customers can also be considered in the models. Through that, a decreased transporter travels on-road as well as decreased $\mathrm{CO}_{2}$ emission could be realized, which are also the main targets in the circular economy.

Author Contributions: Conceptualization, D.İ. and B.Y.E.; data curation, D.İ. and B.Y.E.; formal analysis, D.İ. and B.Y.E.; project administration, B.Y.E.; writing-original draft, D.İ.; writing-review and editing, D.I.., B.Y.E., S.P. and V.K. All authors have read and agreed to the published version of the manuscript.

Funding: This research was funded by Newton Katip Celebi, TUBITAK and the Royal Academy of Engineering (Industry-Academia Partnership Programme 2018/2019, Grant No. 4180046). 
Institutional Review Board Statement: Not Applicable.

Informed Consent Statement: Not applicable.

Data Availability Statement: Data sharing not applicable.

Conflicts of Interest: The authors declare no conflict of interest.

\section{References}

1. Verhoef, P.C.; Kannan, P.K.; Inman, J.J. From Multi-Channel Retailing to Omni-Channel Retailing. J. Retail. 2015, 91, 174-181. [CrossRef]

2. Brynjolfsson, E.; Hu, Y.J.; Rahman, M.S. Competing in the Age of Omnichannel Retailing. MIT Sloan Manag. Rev. 2013, 54, 23-29.

3. Piotrowicz, W.; Cuthbertson, R. Introduction to the Special Issue Information Technology in Retail: Toward Omnichannel Retailing. Int. J. Electron. Commer. 2014, 18, 5-16. [CrossRef]

4. World Trade Organization. E-Commerce, Trade and the Covid-19 Pandemic. Available online: https://www.wto.org/english/ tratop_e/covid19_e/ecommerce_report_e.pdf (accessed on 20 February 2021).

5. Beck, N.; Rygl, D. Categorization of multiple channel retailing in Multi-, Cross-, and Omni-Channel Retailing for retailers and retailing. J. Retail. Consum. Serv. 2015, 27, 170-178. [CrossRef]

6. Wisner, J.D. A Structural Equation Model of Supply Chain Management Strategies and Firm Performance. J. Bus. Logist. 2011, 24, 1-26. [CrossRef]

7. Mangal, D.; Chandna, P. Inventory Control in Supply Chain through Lateral Transshipment—A Case Study in Indian Industry. Int. J. Eng. Sci. 2009, 3, 443-457.

8. Belgasmi, N.; Ben Said, L.; Ghédira, K. Evolutionary multiobjective optimization of the multi-location transshipment problem. Oper. Res. 2008, 8, 167-183. [CrossRef]

9. Ekren, B.Y.; Heragu, S. Simulation based optimization of multi-location transshipment problem with capacitated transportation. In Proceedings of the Winter Simulation Conference, Miami, FL, USA, 7-10 December 2008; IEEE: Danves, MA, USA, 2008; pp. 2632-2638.

10. Geissdoerfer, M.; Savaget, P.; Bocken, N.M.P.; Hultink, E.J. The Circular Economy-A new sustainability paradigm? J. Clean. Prod. 2017, 143, 757-768. [CrossRef]

11. Zink, T.; Geyer, R. Circular Economy Rebound. J. Ind. Ecol. 2017, 21, 593-602. [CrossRef]

12. Haupt, M.; Vadenbo, C.; Hellweg, S. Do We Have the Right Performance Indicators for the Circular Economy? Insight into the Swiss Waste Management System. J. Ind. Ecol. 2016, 21, 615-627. [CrossRef]

13. Blomsma, F.; Brennan, G. The Emergence of Circular Economy: A New Framing Around Prolonging Resource Productivity. J. Ind. Ecol. 2017, 21, 603-614. [CrossRef]

14. Pagoropoulos, A.; Pigosso, D.C.A.; McAloone, T.C. The Emergent Role of Digital Technologies in the Circular Economy: A Review. Procedia CIRP 2017, 64, 19-24. [CrossRef]

15. Rigby, D. The Future of Shopping. Harvard Business Review. Available online: https://hbr.org/2011/12/the-future-of-shopping (accessed on 1 March 2021).

16. Frazer, M.; Stiehler, B. Omnichannel retaılıng: The merging of the onlıne and off-line environment. In Proceedings of the Global Conference on Business and Finance, Honolulu, HI, USA, 6-9 January 2014; pp. 655-657.

17. Rangaswamy, A.; Van Bruggen, G.H. Opportunities and challenges in multichannel marketing: An introduction to the special issue. J. Interact. Mark. 2005, 19, 5-11. [CrossRef]

18. Lazaris, C.; Vrechopoulos, A. From multichannel to "omnichannel" retailing: Review of the literature and calls for research. In Proceedings of the 2nd International Conference on Contemporary Marketing Issues, Athens, Greece, 18-20 June 2014. [CrossRef]

19. Yadav, V.S.; Tripathi, S.; Singh, A.R. Exploring omnichannel and network design in omni environment. Cogent Eng. 2017, 4, 1-16. [CrossRef]

20. Lee, Y.H.; Jung, J.W.; Jeon, Y.S. An effective lateral transshipment policy to improve service level in the supply chain. Int. J. Prod. Econ. 2007, 106, 115-126. [CrossRef]

21. Ekren, B.Y.; Arslan, B. Simulation-based lateral transshipment policy optimization for s, $\mathrm{S}$ inventory control problem in a single-echelon supply chain network. Int. J. Optim. Control. Theor. Appl. 2019, 10, 9-16. [CrossRef]

22. Herer, Y.; Tzur, M.; Yücesan, E. The Multilocation Transshipment Problem. IIE Transactions 2006, 38, 185-200. [CrossRef]

23. Ekren, B.Y.; Ornek, M.A. Determining optimum (s, S) levels of floor stock items in a paint production environment. Simul. Model. Pract Theory 2015, 57, 133-141. [CrossRef]

24. Ekren, B.Y.; Ornek, M.A. Simulation-based inventory control in a chemical industry. In Industrial Engineering Applications in Emerging Countries, 1st ed.; Sabuncuoglu, I., Kara, B.Y., Bidanda, B., Eds.; CRC Press: Boca Raton, FL, USA, 2015.

25. Glazebrook, K.; Paterson, C.; Rauscher, S.; Archibald, T. Benefits of Hybrid Lateral Transshipments in Multi-Item Inventory Systems under Periodic Replenishment. Prod. Oper. Manag. 2014, 24, 311-324. [CrossRef]

26. Zhao, F.; Wu, D.; Liang, L.; Dolgui, A. Lateral inventory transshipment problem in online-to-offline supply chain. Int. J. Prod. Res. 2015, 54, 1951-1963. [CrossRef]

27. İzmirli, D.; Ekren, B.; Kumar, V. Inventory Share Policy Designs for a Sustainable Omni-Chanel E-Commerce Network. Sustainability 2020, 12, 10022. [CrossRef] 
28. Korhonen, J.; Honkasalo, A.; Seppälä, J. Circular Economy: The Concept and its Limitations. Ecol. Econ. 2018, 143, 37-46. [CrossRef]

29. Govindan, K.; Hasanagic, M. A systematic review on drivers, barriers, and practices towards circular economy: A supply chain perspective. Int. J. Prod. Res. 2018, 56, 278-311. [CrossRef]

30. Genovese, A.; Acquaye, A.A.; Figueroa, A.; Koh, S.C.L. Sustainable supply chain management and the transition towards a circular economy: Evidence and some applications. Omega 2017, 66, 344-357. [CrossRef]

31. Soysal, M.; Bloemhof-Ruwaard, J.M.; van der Vorst, J.G.A.J. Modelling food logistics networks with emission considerations: The case of an international beef supply chain. Int. J. Prod. Econ. 2014, 152, 57-70. [CrossRef]

32. Abad-Segura, E.; De La Fuente, A.B.; González-Zamar, M.-D.; Belmonte-Ureña, L.J. Effects of Circular Economy Policies on the Environment and Sustainable Growth: Worldwide Research. Sustainability 2020, 12, 5792. [CrossRef]

33. Milios, L. Towards a Circular Economy Taxation Framework: Expectations and Challenges of Implementation. Circ. Econ. Sustain. 2021, 1-22.

34. Windapo, A.O.; Moghayedi, A. Adoption of smart technologies and circular economy performance of buildings. Built Environ. Proj. Asset Manag. 2020, 10, 585-601. [CrossRef]

35. Nakandala, D.; Lau, H.; Shum, P.K.C. A lateral transshipment model for perishable inventory management. Int. J. Prod. Res. 2017, 55, 5341-5354. [CrossRef]

36. Ekren, B.Y.; Eroğlu, E.; Kazançoğlu, Y.; Kumar, V. Lateral inventory share based business model for IoT enabled sustainable food supply chain network. In Proceedings of the 5th NA International Conference on Industrial Engineering and Operations Management, IEOM Society, Detroit, MI, USA, 9-11 August 2020; pp. 44-54.

37. Ekren, B.Y.; Mangla, S.K.; Turhanlar, E.E.; Kazancoglu, Y.; Li, G. Lateral inventory share-based models for IoT-enabled E-commerce sustainable food supply networks. Comput. Oper. Res. 2021, 130, 105237. [CrossRef]

38. Jose, R.; Panigrahi, S.K.; Patil, R.A.; Fernando, Y.; Ramakrishna, S. Artificial Intelligence-Driven Circular Economy as a Key Enabler for Sustainable Energy Management. Mater. Circ. Econ. 2020, 2, 1-7. [CrossRef]

39. Kleijnen, J.P.C.; Wan, J. Optimization of simulated systems: OptQuest and alternatives. Simul. Model. Pract. Theory 2007, 15, 354-362. [CrossRef] 